\title{
Assessment of Cardiovascular Risk Factors in a Rural Community in the Brazilian State of Bahia
}

\author{
André Costa Matos, A na Marice Ladeia \\ Salvador, Bahia - Brazil
}

\begin{abstract}
Objective - To assess the frequency of cardiovascular risk factors in the rural community of Cavunge, in the Brazilian state of Bahia.

Methods - A cross-sectional study was carried out with 160 individuals (age $\geq 19$ years) randomly drawn from those listed in the population census of the Cavunge Project. The following parameters were studied: arterial hypertension, dyslipidemia, diabetes, obesity, smoking, waist-hip ratio (WHR), physical activity, and overall cardiovascular risk classified according to the Framingham score. The assessing parameters used were those established by the III Brazilian Consensus on Hypertension and the II Brazilian Consensus on Dyslipidemia.
\end{abstract}

Results - Of the randomly drawn individuals, 126 with a mean age of $46.6 \pm 19.7$ years were included in the study, $43.7 \%$ of whom were males. The frequency of arterial hypertension was $36.5 \% ; 20.4 \%$ of the individuals had cholesterol levels $\geq 240 \mathrm{mg} / \mathrm{dL} ; 31.1 \%$ of the individuals had LDL-C levels $>130 \mathrm{mg} / \mathrm{dL} ; 4 \%$ were diabetic; and $39.7 \%$ had a high-risk Framingham score. Abdominal obesity was observed in $41.3 \%$ of the population and in $57.7 \%$ of the females. High caloric-expenditure (HCE) physical activities were performed by $56.5 \%$ of the individuals. The $H C E$ group had a greater frequency of normal triglyceride levels (63\% vs 44\%; $P=0.05)$, no diabetes, and WHR tending towards normal (46\% vs $27 \%, P=0.08)$ as compared with those in the low caloric-expenditure group.

Conclusion-Cardiovascular risk factors, such as hypertension and hypercholesterolemia, are frequently found in rural communities. The greatest frequency of normal triglyceride levels and normal WHR in the HCE group reinforces the association between greater caloric expenditure and a better risk profile.

Keywords: cardiovascular risk factors; rural community; epidemiology

Faculdade de Medicina da UFBA.

Mailing address: Ana Marice Ladeia - Rua Altino Seberto de Barros 241/560 41850-010 - Salvador, BA, Brazil - E- mail: anais@e-net.com.br

English version by Stela Maris C. e Gandour
Despite the decrease in mortality due to cardiovascular diseases concomitant with the intensification in controlling arterial hypertension in developed countries ${ }^{1,2}$, cardiovascular diseases still remain the major cause of death ${ }^{3}$. In Brazil, these diseases not only represent an important cause of morbidity and mortality ${ }^{4,5}$, but are also associated with high cost, both social and those resulting from hospitalizations and retirement ${ }^{6}$.

In different regions of Brazil, great cultural and socioeconomic differences are observed, especially between the urban and rural populations ${ }^{7}$. These aspects may interfere with the cardiovascular risk profile of individuals. Socioeconomic differences, for example, are associated with variations in blood pressure in different populations as seen in the variation of prevalence reported in some studies performed in different regions, such as the southern and northeastern regions ${ }^{8}$. In this context, while most cardiovascular risk factors are more frequent in large cities ${ }^{9-14}$, systemic arterial hypertension associated with a high ingestion of sodium seems to be common in rural populations of the Brazilian northeastern region ${ }^{15,16}$.

\section{Methods}

In this cross-sectional study, 160 adult individuals were randomly drawn. They were at least 19 years old and represented $25.6 \%$ of the individuals in that age group residing in the village of Cavunge, Ipecaetá, in the Brazilian state of Bahia. The individuals were randomly drawn from the databank of the population census performed in the $\mathrm{Ca}$ vunge Project [a research project financed by $\mathrm{CNPq}$ (National Council of Research), which studies the latent infection and the subclinical form of visceral leishmaniasis in the population of the village of Cavunge]. Cavunge is a small rural community located in the semi-arid northeastern region of the state of Bahia, $162 \mathrm{~km}$ away from the city of Salvador, the capital of the state. The village of Cavunge has an area of $63.5 \mathrm{~km}^{2}$.

The following individuals were excluded from the study: those with physical or mental disabilities that could jeopardize the procedures or who could not understand the 
written formal consent, and those residing in the village for less than 3 years.

The individuals randomly drawn were invited to a lecture aimed at providing the community with explanations about the study and with guidance about the conditions necessary for the investigation (12-hour fasting, no physical exercise, no alcoholic beverages or coffee) ${ }^{17}$. The project was approved by the Committee on Ethics in Research of the CPqGM-Fiocruz. All individuals included in the study signed the written consent.

The following cardiovascular risk factors were analyzed: 1) age, defined as a risk factor in males $>45$ years and females $>55$ years; 2 ) race, in which the classification was based on subjective criteria according to the scale: white, mulatto, and black; 3) male sex; 4) familial history of early atherosclerotic disease (E-ACD) when affecting males aged less than 55 years and females aged less than 65 years; 5) arterial hypertension (AH) defined as systolic blood pressure $\geq 140 \mathrm{mmHg}$ or diastolic blood pressure $\geq 90$ $\mathrm{mmHg}$, or both, or use of antihypertensive drugs; 3 measurements at 3-minute intervals were taken in the right arm with a properly calibrated aneroid sphygmomanometer with the patient in the sitting position according to the procedure specified in the III CBHA (Brazilian Consensus on Arterial Hypertension) ${ }^{17}$; 6) diabetes mellitus, defined as fasting blood glucose above $140 \mathrm{mg} / \mathrm{dL}$ or use of glucose-lowering drugs or insulin, or both; 7) obesity, defined as body mass index $(\mathrm{BMI}) \geq 30 \mathrm{~kg} / \mathrm{m}^{2}$; individuals with $\mathrm{BMI}<25$ and between 25 and 29.99 were respectively classified as normal and overweight. Weight and height were measured using an anthropometric scale in dressed patients not wearing coats or shoes; 8) abdominal obesity assessed by the waist-hip ratio (WHR); for males, this ratio was corrected with the formula $(-0.02265+1.00459 \times$ WHR $)$ used by Larsson et $\mathrm{l}^{18}$, and the ratios $>0.95$ and 0.85 were considered risk factors for males and females, respectively. The reference point used to measure the waist was either the umbilicus or the narrowest region (visible waist) of the abdomen when that region did not coincide with the region of the umbilicus ${ }^{19}$. The pubic symphysis and the most protuberant point of the gluteal region were the reference points for hip measurement ${ }^{19}$; 9) smoking, considered present in individuals reporting smoking until the day of the interview; 10) physical activity classified into the 2 following groups: high caloric expenditure (HCE), individuals reporting participation in physical exercises at least 3 times a week, or those whose work involved a high caloric expenditure (carpenter, vulcanizer, hard laborer, or agriculturist) ${ }^{20}$; and low caloric expenditure (LCE), individuals not participating in physical exercises according to a predefined criterion, or those whose work involved low cal oric expenditure (driver, salesperson, waiter, wall painter, domestic workers, mechanic, and joiner) ${ }^{20}$; 11) menopause, defined as lack of menstruation for more than 3 months in females $>45$ years, once other causes of amenorrhea were excluded.

The lipid profile included the following tests: total cholesterol (TC), HDL- cholesterol (HDL-C), LDL- cholesterol
(LDL-C), and triglycerides measured after a fasting period of at least 12 hours. Blood was drawn at the headquarters of the Cavunge Project, and the biochemical analysis was performed in a specialized laboratory in Salvador. The parameters used were those established by the II Brazilian Consensus on Dyslipidemia $^{21}$. Total cholesterol and triglycerides were measured with an enzymatic method, HDL-cholesterol was measured with precipitation, and LDL-cholesterol was calculated with the Friedewald formula [LDL-C $=$ TC - (HDL$\mathrm{C}+\mathrm{TG} / 5)$ ] for triglyceride levels $\leq 400 \mathrm{mg} / \mathrm{dL}^{22}$.

Based on the Framingham Study score ${ }^{23}$, the overall cardiovascular risk of each individual was calculated. In its analysis, the Framingham Study score comprises the following risk factors: age, total cholesterol, HDL-C, systolic blood pressure, diabetes, and smoking with a specific level for each item. Addition of the points provided the overall score of each individual. The level obtained was listed in a table of relative risk for coronary artery disease identified by a numeric scale, in addition to the absolute risk for coronary events in 10 years ${ }^{24}$.

Data were analyzed with SPSS (Statistical Package for Social Science) software. The Student $t$ test was used for analyzing the means and the chi-square test for the proportions. In a $2 \times 2$ table, the Yates correction and Fisher exact test were used when the frequencies expected were lower than 5 in 1 or more cells, respectively. In those tests, the difference was considered significant when the probability (P) of type I error was $\leq 5 \%$.

\section{Results}

Of the 160 individuals randomly drawn, 143 came for the interview, but, in 17 of them, the blood sample underwent hemolysis. The final sample comprised $126(78.8 \%)$ individuals, whose mean age was $46.6 \pm 19.2$, of whom $43.7 \%$ were males and $56.2 \%$ were females, $40.8 \%$ of whom were menopausal and not receiving hormone replacement therapy. The following frequencies were observed: systemic arterial hypertension, 36.5\%; diabetes mellitus, 4\%; and smoking, $11.9 \%$. Obesity was observed in $7.9 \%$ and overweight was observed in $27.8 \%$ of the individuals. Abdominal obesity, the most prevalent risk factor, was identified in $52(41.3 \%)$ participants. These and other demographic and clinical characteristics are shown in table I. When comparing the sexes, only abdominal obesity $(57.7 \%$ vs $20 \%, \mathrm{P}<0.001)$ and smoking $(18.2 \%$ vs $7 \%, \mathrm{P}=0.05)$ had a statistically significant difference. Table I also shows the mean values of the biochemical parameters, and only the following were statistically different between the sexes: total cholesterol $(218 \pm 44.3$ vs $188.3 \pm 53.2 ; \mathrm{P}=0.001)$, LDL-C $(128 \pm 44.3 \mathrm{vs} 102 \pm 47.2 ; \mathrm{P}<0.002)$, and glycemia $(96.7 \pm 43.9 \mathrm{vs}$ $84.5 \pm 15.3 ; \mathrm{P}=0.05)$.

In the distribution by band of lipid profile, $48.4 \%$ of the individuals had TC $<200 \mathrm{mg} / \mathrm{dL}$ and $20.4 \%$ had TC $\geq$ $240 \mathrm{mg} / \mathrm{dL}$, and $68.9 \%$ and $85.7 \%$ had, respectively, normal levels of LDL-C and triglycerides (figs. 1, 2, and 3). When comparing the sexes, males had a greater frequency 


\begin{tabular}{|lr|}
\hline \multicolumn{2}{|c|}{$\begin{array}{c}\text { Table I }- \text { Demographic and clinical characteristics of the population } \\
\text { studied }\end{array}$} \\
\hline Total & 126 \\
Age (mean \pm standard deviation*) & \\
Race & $\mathrm{n}(\%)$ \\
White & $25(19.8)$ \\
Mulatto & $79(62.7)$ \\
Black & $22(17.5)$ \\
Clinical variables $(*)$ & \\
SBP $(\mathrm{mmHg})$ & $128.1 \pm 19.8$ \\
DBP $(\mathrm{mmHg})$ & $78.2 \pm 12.4$ \\
BMI $\left(\mathrm{kg} / \mathrm{m}^{2}\right)$ & $24.2 \pm 3.8$ \\
Triglycerides & $128.6 \pm 76.5$ \\
Total cholesterol & $205 \pm 49.9$ \\
LDL-C & $116.7 \pm 47.2$ \\
HDL-C & $70 \pm 16.6$ \\
Glucose & $91.4 \pm 34.9$ \\
& $\mathrm{n}(\%)$ \\
Early CAD & $35(27.8)$ \\
Hypertension & $46(36.5)$ \\
Obesity & $10(7.9)$ \\
Abdominal obesity & $52(41.3)$ \\
Diabetes & $5(4)$ \\
Menopause & \\
Smoking & $15(11.9)$ \\
CE/PC** & \\
High expenditure & $70(56.5)$ \\
Low expenditure & $54(43.5)$ \\
\hline ** Caloric expenditure/professional category; SBP- systolic blood pressure; \\
DBP- diastolic blood pressure. \\
\hline
\end{tabular}

of TC $<200(67.3 \%$ vs $33.8 \% ; \mathrm{P}<0.001)$ and a lower frequency of TC ranging from 200 to $239(14.5 \%$ vs $43.7 \% ; \mathrm{P}<0.001)$ than females did (fig. 1). No statistically significant difference was observed between the sexes for the other lipid variables.

The caloric expenditure was not estimated in 2 individuals because they did not have a well-defined occupational activity. The distribution of that variable in regard to the sexes was different: $72.2 \%(39 / 54)$ of the males had HCE and $27.8 \%(15 / 54)$ had LCE, while $44.3 \%(31 / 70)$ of the

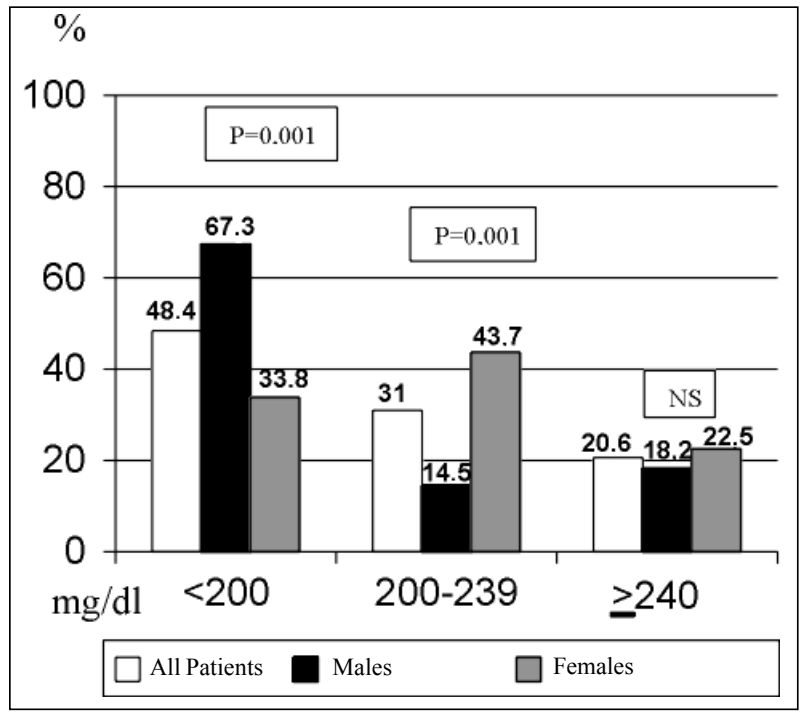

Fig. 1 - Distribution of the population studied by TC range and by sex. females had HCE and 55.7\% (39/70) had LCE ( $\mathrm{P}=0.002)$.

Physical activity was correlated with other clinical variables, and the distributions of diabetes mellitus (HCE $0 \%$; LCE $5 / 54=9.3 \%)(\mathrm{P}=0.01)$ (tab. II $)$ and dyslipidemia were different in the HCE and LCE groups. In the individuals with normal triglyceride levels, a greater frequency of $\mathrm{HCE}(63 / 107$ $=58.9 \%)$ and lower of LCE $(44 / 107=41.1 \%)$ was observed; however, in individuals with high levels of triglycerides, a greater frequency of LCE $(9 / 13=69.2 \%)$ and a lower frequency of $\operatorname{HCE}(4 / 13=30.8 \%)(\mathrm{P}=0.05)$ were observed (tab II). Likewise, individuals with normal WHR had a greater frequency of HCE $(46 / 73=63 \%)$ and lower frequency of $\operatorname{LCE}(27 / 73=27 \%)$, while those with risky WHR had an

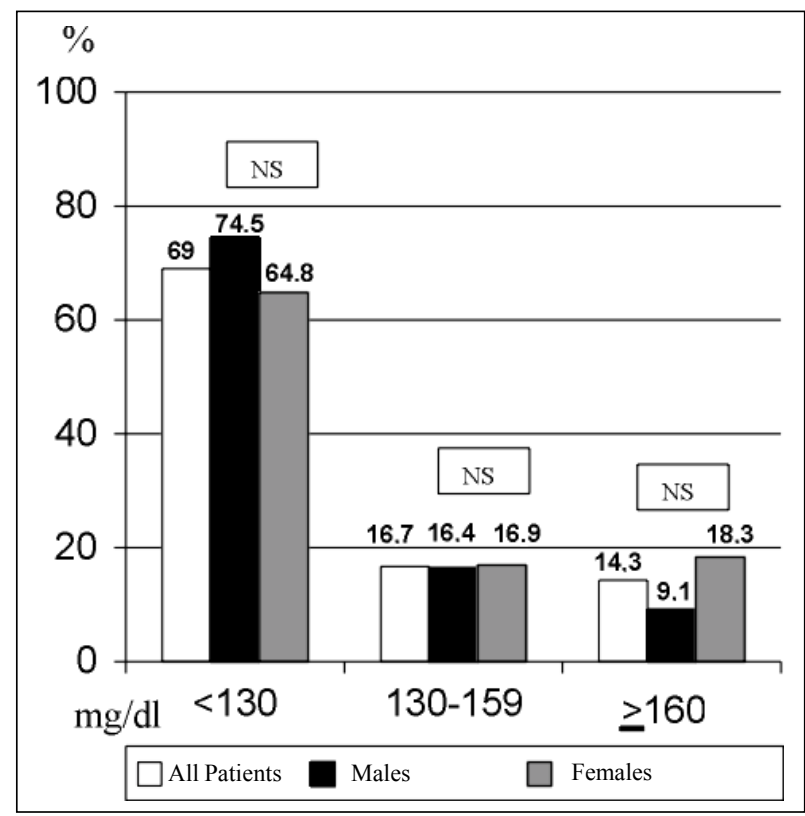

Fig. 2 - Distribution of the population studied by LDL-C range and by sex.

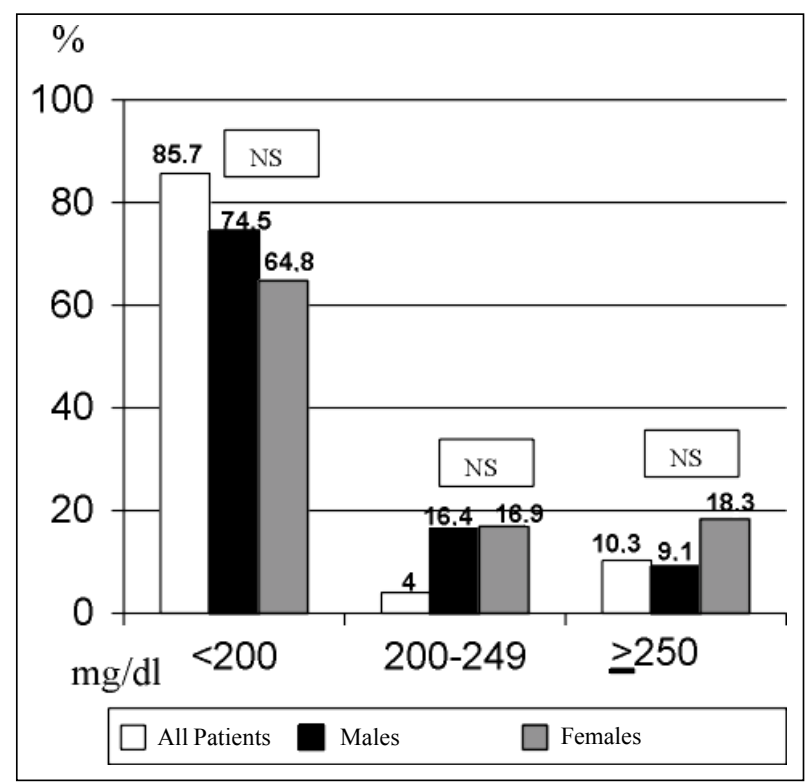

Fig. 3 - Distribution of the population studied by triglyceride range and by sex. 


\begin{tabular}{|c|c|c|c|}
\hline Variable & HCE & LCE & $\mathrm{p}$ \\
\hline \multicolumn{4}{|l|}{ Diabetes mellitus } \\
\hline Yes & 0 & 5 & 0.01 \\
\hline No & 70 & 49 & \\
\hline \multicolumn{4}{|l|}{ LDL-C (mg/dL) } \\
\hline Normal $(<130)-\mathrm{a}$ & 47 & 38 & \\
\hline Lim. elevated (130-159) - b & 16 & 5 & $\mathrm{bxc}=0.02$ \\
\hline Elevated $(\geq 160)-c$ & 7 & 11 & \\
\hline \multicolumn{4}{|l|}{ Triglycerides (mg/dL) } \\
\hline Normal $(<200)-\mathrm{d}$ & 63 & 44 & \\
\hline Lim. elevated (200-249) - e & 3 & 1 & $\mathrm{dxf}=0.05$ \\
\hline Elevated $(\geq 250)-f$ & 4 & 9 & \\
\hline \multicolumn{4}{|l|}{ WHR } \\
\hline Normal & 46 & 27 & 0.08 \\
\hline Risky & 24 & 27 & \\
\hline \multicolumn{4}{|l|}{ Obesity (males) } \\
\hline Normal - g & 31 & 6 & $\mathrm{gxh}=0.01$ \\
\hline Overweight $-\mathrm{h}$ & 7 & 8 & \\
\hline Obese $-\mathrm{i}$ & 1 & 1 & \\
\hline $\begin{array}{l}\text { HCE- high caloric expenditure; } \\
\text { hip ratio. }\end{array}$ & ow ca & enditur & HR- waist- \\
\hline
\end{tabular}

inverse frequency distribution (HCE $24 / 51=47 \%$; LCE $27 / 51$ $=53 \%)(\mathrm{P}=0.08)(\mathrm{tab}$. II). In regard to males, those in the HCE group had a greater frequency of normal weight $(31 / 38$ $=81.6 \%)$ and a lower frequency of overweight $(7 / 38=$ $18.4 \%$ ), contrary to that observed in the LCE group males (57.1\% had overweight, and $42.9 \%$ had normal weight, $\mathrm{P}=0.01$ ) (tab. II). Among males, only 2 (3.6\%) were obese.

The cutoff point of HDL-C was elevated from 35 to 40, because this is the recommendation of the current consensus on dyslipidemia. In ourstudy, only 6(4.8\%) individuals had HDLClevels below $35 \mathrm{mg} / \mathrm{dL}$; when the cutoff point was elevated to $40 \mathrm{mg} / \mathrm{dL}$, a $1.5 \%$ increase occurred, but no difference was observed in the distribution of this lipid variable in the groups of caloric expenditure according to physical activity.

The analysis of the overall cardiovascular risk indicated that $39.7 \%$ of the population had a high risk for coronary artery disease in 10 years. The comparison between the sexes showed no significant difference in risk stratification (fig. 4). However, a significant difference was observed between the profiles of menopausal and nonmenopausal females, showing that most females in the former group $(79.3 \%)$ had a high risk for coronary artery disease in 10 years, but only $9.5 \%$ of the females in the latter group had a similar risk $(\mathrm{P}<0.001)$.

\section{Discussion}

The results of this study show a high frequency (36.5\%) of systemic arterial hypertension in the population studied. This frequency was slightly higher than that of other urban Brazilian population groups, such as those from the cities of Piracicaba ${ }^{25}$, Catanduva ${ }^{26}$, and Araraquara $^{27}$ in inner São Paulo state, whose frequencies of systemic arterial hypertension were, respectively, $32.7 \%$, $31.5 \%$, and $28.3 \%$. A study ${ }^{15}$ carried out in a community in the western region of the State of Bahia in 1977, whose criteria for diagnosing systemic arterial hypertension were blood pressure levels $>160 / 95 \mathrm{mmHg}$, reported that $18.2 \%$ of the population were hypertensive. When individuals with blood pressure levels $>140 / 95 \mathrm{~mm} \mathrm{Hg}$ were also included, a prevalence of $31.4 \%$ was observed. The criteria used in this study carried out in the State of Bahia may have favored the underestimation of the frequency of systemic arterial hypertension; however, when comparing our data with those of the studies carried out in the cities of Piracicaba ${ }^{25}$ and Catanduva ${ }^{26}$, whose diagnostic criteria for systemic arterial hypertension were similar to those of this study, we also observed that, in rural communities, systemic arterial hypertension is a very common clinical condition, as seen in some studies in other countries, such as Spain and Italy, whose prevalences of the disease were $41 \%$ and $45 \%$, respectively 28,29 .

Salt ingestion is known to be strongly correlated with an increase in the prevalence of systemic arterial hypertension, as reported in a Japanese study ${ }^{30}$, in which the prevalence of the disease is $21 \%$ in the southern region, where the mean salt ingestion is $13 \mathrm{~g}$, and $38 \%$ in the northern region, where the salt ingestion doubles. Therefore, the Brazilian northeastern habit of salting food for preservation, which is very common in rural populations, is believed to explain the high prevalence of systemic arterial hypertension found in this study.

The analysis of the lipid profile in this study showed that most of the population studied had LDL-C and triglyceride levels within the desired range, as well as extremely elevated mean levels of HDL-cholesterol; the $20.4 \%$ frequency of hypercholesterolemia (TC $\geq 240 \mathrm{mg} / \mathrm{dL}$ ) was greater than that found in other Brazilian populations, such as in a study about the Brazilian capitals, whose overall frequency of hypercholesterolemia was $8.8 \%{ }^{31}$. Considering the TC levels greater than $200 \mathrm{mg} / \mathrm{dL}$, the $51.6 \%$ prevalence found in this study was greater than the $40 \%$ prevalence found in the city of Porto Alegre and the

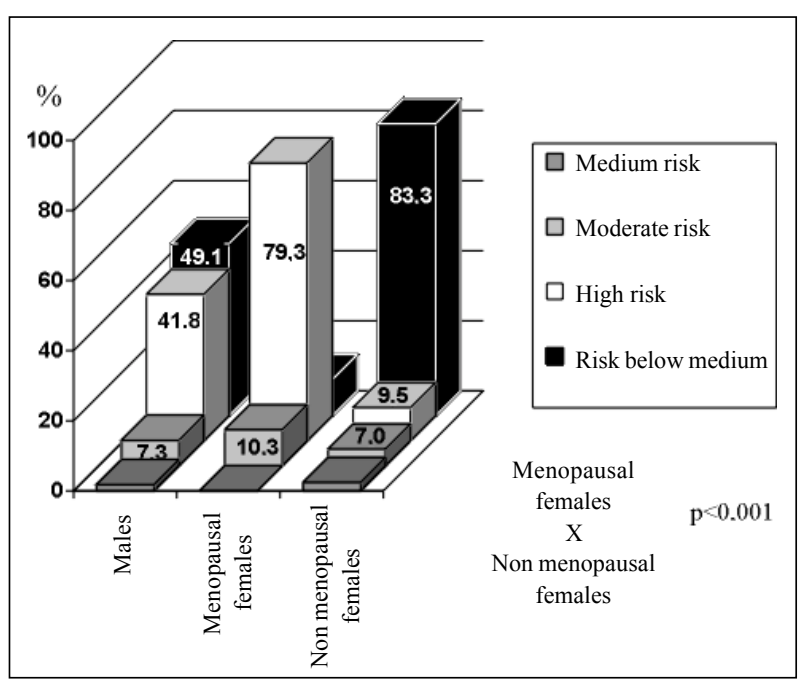

Fig. 4-Distribution of the overall cardiovascular risk by sex and in the menopausal females. 
$36.7 \%$ prevalence found in the city of Salvador ${ }^{31}$. The dietary habits of the population studied may once again have contributed to an increase in the frequency of hypercholesterolemia, because, in rural area, the use of saturated fat in food preparation is common. However, the low frequency of hypertriglyceridemia (14\%) and low levels of HDL-C (4.8\%) are noteworthy. We believe that the professional occupation of these individuals, most of whom are agriculturists, with high caloric expenditure activities may justify these results ${ }^{32}$. The comparative analysis between the high caloric expenditure and low caloric expenditure groups showed that most individuals with normal levels of triglycerides had professional activities requiring a high caloric expenditure, while in the group with high LDLC levels, low caloric expenditure activities predominated.

In this study, the importance of physical activity as an indicator of better cardiovascular risk profile ${ }^{32}$ is confirmed by the tendency towards a lower frequency of abdominal obesity in the high caloric expenditure group and the higher frequency of males with normal weights. In addition, as compared with males, females had a greater frequency of low caloric expenditure activities, a higher frequency of abdominal obesity, greater mean levels of total cholesterol and LDL-C, and also a lower frequency of cholesterol levels within the normal range. Menopause may also have contributed to the less favorable cardiovascular risk profile in females, because $40.8 \%$ of the females in this study already were menopausal, and $79.3 \%$ were at high risk for coronary artery disease in 10 years estimated by the Framingham Study score ${ }^{25}$ as compared with only $9.5 \%$ in the group of childbearing-age females.

In this study, due to operational questions, the WHO diagnostic criterion, which requires a single glucose measurement (fasting blood glucose $>140 \mathrm{mg} / \mathrm{dL}$ ) for diabetes mellitus was used instead of that of the Brazilian Consensus on Diabetes, which requires 2 measurements of fasting blood glucose with values greater than $126 \mathrm{mg} / \mathrm{dL}$ ${ }^{33}$. The use of the WHO criterion may have resulted in an underestimation of the incidence of diabetes mellitus. However, the low $4 \%$ prevalence of diabetes mellitus, lower than the mean $7.6 \%$ prevalence in the Brazilian population ${ }^{33}$, is believed to be justified by the occupational high caloric expenditure ${ }^{32}$. This is also evident in the comparison between the sexes, when a higher incidence of diabetes is found in females, who, in this study, had fewer high caloric expenditure professional activities than males did, and had a higher incidence of abdominal obesity, which is a well-known risk factor for the plurimetabolic syndrome and type 2 diabetes mellitus ${ }^{34}$. In addition, no case of diabetes was observed in the high caloric expenditure group.

Despite the existence of some relevant limitations, such as the different demographic characteristics between the populations of Cavunge and Framingham, the use of the Framingham Study risk score in this study brought relevant information from the preventive and economic viewpoints. The assessment of the overall cardiovascular risk showed that $39.7 \%$ of the population studied had a high risk for coronary events in 10 years. Considering the mean age of 46.6 years, the finding that more than one third of the population studied has its professional activity and remaining productive period limited to 10 years is very disturbing. In addition, the impact of the association of multiple risk factors in the early development of CAD and the need for their early identification and adequate control have been well established ${ }^{35}$.

From the methodological point of view, a $21.2 \%$ loss was observed in the initial sample due to nonadherence of select individuals (10.6\%) and to hemolysis of the blood sample (10.6\%). Sample losses around $20 \%$ may constitute a selection bias; however, when these losses are random, they are interpreted as a representative subsample of the original sample, that does not significantly interfere with the interpretation of the results ${ }^{36}$.

Our results showed that the risk factors for cardiovascular diseases with a high prevalence in urban populations are also frequently found in rural communities. On the other hand, the lecture about risk factors delivered to the community in the initial phase of this study showed that, although the population studied completely lacked knowledge about preventive measures, they also avidly desired information about health promotion. These data point to the need for prevention and control educational programs in these communities with a special emphasis on dietary habits, involving not only the regional health care professionals, but the population in general, which will act as information-proliferating agents.

\section{Acknowledgment}

We thank Drs. José Tavares-Neto, Amaurí A. Matos, Danilo C. do Espírito Santo, Eduardo C. Matos, Igor G. Barreto, Jailson A. Silva, Joelande Correia, Luiz Fernando Adan, Luiz Sergio A. Filho, Moacir F. Júnior, Patrícia Ribeiro, and Ronald M. C. Trindade for their technical support, and Laboratório DNA for the biochemical support.

\section{References}

1. World Health Organization International Society of Hypertension. Guidelines for the Management of Hypertension. Hypertens 1999; 17: 151-183.

2. The Catalonia declaration-investing in heart health. Preface. In: Declaration of the Advisory Board of the Second International Heart Conference. Barcelona, Catalonia, 1995: 1-3.
3. US Department of Health and Human Services. Morbidity and Mortality Chartbook on Cardiovascular, Lung and Blood Diseases, 1990. Bethesda, US Department of Health and Human Services, Public Health Service, National Institutes of Health, 1990.

4. Ministério da Saúde. Sistema de Informações Hospitalares do SUS - SIH/SUS. 
Morbidade hospitalar proporcional por grupos de doenças. Vol. 06/11/00 Ministério da Saúde. Brasil, 1997.

5. Lotufo PA, Lolio CA. Tendências de evolução da mortalidade por doenças cardiovasculares: o caso do estado de São Paulo. In: Monteiro CA. Velhos e Novos Males da Saúde no Brasil. São Paulo: hucitec nupens/usp, 1995: 279-88.

6. Ministério da Saúde. Coordenação de Doenças Cardiovasculares no Brasil. Sistema Único de Saúde-SUS. Ficha catalográfica 36p. Brasília, 1993.

7. Lacaz CS. Os fatos essenciais da geografia humana. O homem e seu ambiente. População, tipos humanos, habitat e subdesenvolvimento. A assistência médica no Brasil. Movimentos migratórios e doenças infecciosas e parasitárias. Alimentação e endemias rurais. In: LacazCdS, Baruzzi RG, Jr. WS. Introduçãoà Geografia Médica do Brasil. São Paulo: Hicitec Abrasco, 1972: 126-178.

8. Lessa I. Epidemiologia da hipertensão arterial. In: Lessa I. O Adulto Brasileiro e as Doenças da Modernidade: Epidemiologia das Doenças Crônicas não Transmissíveis. São Paulo: Hicitec Abrasco, 1998: 77-96.

9. Dash SC, Sundaram KR, Swain PK. Blood pressure profile, urinary sodium and body weight in the 'Oraon' rural and urban tribal community. J Assoc Physicians India 1994; 42: 878-80.

10. Sever PS, Gordon D, Peart WS, Beighton P. Blood pressure and its correlates in urban and tribal Africa. Lancet 1980; 2(8185): 60-4.

11. Chadha SL, Gopinath N, Shekhawat S. Urban-rural differences in the prevalence of coronary heart disease and its risk factors in Delhi. Bull World Health Organ 1997; $75: 31-8$.

12. Garcia-Palmieri MR, Sorlie PD, Havlik RJ, Costas RJ, Cruz-Vidal M. Urban-rura differences in 12 year coronary heart disease mortality: the Puerto Rico Heart Health Program. J Clin Epidemiol 1988; 41: 285-92.

13. Singh RB, Sharma JP, Rastogi V, et al. Prevalence of coronary artery disease and coronary risk factors in rural and urban populations of North India. Eur Heart J 1997; 18: 1728-35.

14. Singh RB, Bajaj S, NiazMA, Rastogi SS, Moshiri M. Prevalence of type 2 diabete mellitus and risk of hypertension and coronary artery disease in rural and urban population with low rates of obesity. Int J Cardiol 1998; 66: 65-72

15. Barreto ML, Meira RL. Hipertensão Arterial em uma comunidade do oeste do estado da Bahia (Brasil). Arq Bras Cardiol. 1980; 34: 363-66.

16. Formigli VL, Jacobina RR, Noblat AC, Nascimento Sobrinho CL, Noblat LA. Hipertensão arterial em adultos de um bairro de Salvador, Bahia. Rev Baiana de Saúde Públ 1998/1999; 23: 7-20.

17. IIIConsenso Brasileiro de Hipertensão Arterial-CBHA. Campos do Jordão(SP) 1998.

18. Larsson B, Bengtsson C, Bjorntorp P, et al. Is abdominal body fat distribution a major explanation for the sex difference in the incidence of myocardial infarction? The study of men born in 1913 and the study of women, Goteborg, Sweden. Am J Epidemiol 1992; 135: 266-73.

19. Ladeia AM. Prevenção secundária da doença aterosclerótica coronariana na
Bahia: Avaliação da atitude dos cardiologistas e do controle dos fatores de risco. Salvador: Universidade Federal da Bahia, 1998: 128.

20. Filho JAO, Salvetti XM. Programas não supervisionados de reabilitação cardiovascular - abordagem da prescrição de exercícios. Rev Soc Cardiol Estado de São Paulo 1996; 6: 31-9.

21. $2^{\circ}$ Consenso Brasileiro sobre Dislipidemias - Detecção - Avaliação - Tratamento. Arq Bras Cardiol 1996; 67: 1-16.

22. Friedewald WT, Levy RI, Fredrickson DS. Estimation of concentrations of low density cholesterol in plasma without the use of preparative ultracentrifuge. Clin Chemi 1972; 18: 499-502.

23. Schmidt A, Nobre F, Mion Jr D. Risco cardiovascular global: da teoria aplicada à prática. In: Nobre F, ed. Risco Cardiovascular Global: da Teoria à Prática. São Paulo: Lemos-Editorial, 2000: 13-24.

24. Wilson PWF, D'agostino RB, Levy D, Belangen AM, Silbershat H, Kannel WB. Prediction of coronary heart disease using risk factor categories. Circulation 1998; 97: 1837-47

25. Ayres JEM. Prevalência da hipertensão arterial na cidade de Piracicaba. Arq Bras Cardiol 1991; 57: 33-36

26. Freitas OC, de Carvalho FR, Neves JM, et al. Prevalência de hipertensão arterial sistêmica na população urbana de Catanduva, SP. Arq Bras Cardiol 2001; 77 : $9-15$.

27. Lolio CA. Prevalência de hipertensão arterial em Araraquara. Arq Bras Cardiol 1990; 55: 167-73.

28. Segura FA, Rius MG. Cardiovascular risk factors in a rural population of CastillaLa Mancha. Rev Esp Cardiol 1999; 52: 577-88.

29. Pasini GF, Donato F, Buizza MA, et al. Prevalence of risk factors for coronary heart disease in a mountain community in northern Italy. G Ital Cardiol 1999: 891-7.

30. Dawber TR, Kannel WB, Kagan A, Donadebian RK, McNamara PM, Pearson G. Environmental factors in hypertension. In: T SRP, ed. The Epidemiology of Hypertension. New York: Grune and Stratton, 1967: 255-8.

31. Guimarães CG, Lima M, Mota E, etal. The cholesterol level of a selected Brazilian salaried population: biological and socioeconomic influences. CVD Prevention 1998; 1: 273-80.

32. Faludi AA, Mastrocolla LE, Bertolami MC. Atuação do exercício físico sobre os fatores de risco para doenças cardiovasculares. Rev Soc Cardiol Estado de São Paulo 1996: 6.

33. Consenso Brasileiro Sobre Diabetes. Recomendações da Sociedade Brasileira de Diabetes 2000

34. Reaven GM. Role of insulin resistance in human disease. Diabetes 1988; 37 : 1595-607.

35. YusufHR, Giles WH, Croft JB, Anda RF, Casper ML. Impact of multiple risk factor profiles on determining cardiovascular disease risk. Prev Med 1998; 27: 1-9.

36. Pereira MG. Seleção dos participantes para estudo. In: Pereira MG, ed. Epidemiologia - Teoria e Prática. Rio de Janeiro: Guanabara Koogan, 1995: 337-57. 